\title{
Spotlight on dinutuximab in the treatment of high-risk neuroblastoma: development and place in therapy
}

This article was published in the following Dove Press journal:

Biologics:Targets and Therapy

\author{
Michelle E Keyel ${ }^{1,2}$ \\ C Patrick Reynolds ${ }^{1-4}$ \\ 'Cancer Center, ${ }^{2}$ Department of \\ Pediatrics, ${ }^{3}$ Department of Internal \\ Medicine, ${ }^{4}$ Department of Cell Biology \\ \& Biochemistry, School of Medicine, \\ Texas Tech University Health Sciences \\ Center, Lubbock, TX, USA
}

Correspondence: C Patrick Reynolds Cancer Center, School of Medicine, Texas Tech University Health Sciences Center, 360I, 4th Street Lubbock, TX 79430, USA

Email Patrick.Reynolds@ttuhsc.edu

\begin{abstract}
Neuroblastoma (NB) is a pediatric cancer of the sympathetic nervous system which accounts for $8 \%$ of childhood cancers. Most NBs express high levels of the disialoganglioside GD2. Several antibodies have been developed to target GD2 on NB, including the human/ mouse chimeric antibody ch14.18, known as dinutuximab. Dinutuximab used in combination with granulocyte-macrophage colony-stimulating factor, interleukin-2, and isotretinoin (13-cisretinoic acid) has a US Food and Drug Administration (FDA)-registered indication for treating high-risk NB patients who achieved at least a partial response to prior first-line multi-agent, multimodality therapy. The FDA registration resulted from a prospective randomized trial assessing the benefit of adding dinutuximab + cytokines to post-myeloablative maintenance therapy for high-risk NB. Dinutuximab has also shown promising antitumor activity when combined with temozolomide and irinotecan in treating NB progressive disease. Clinical activity of dinutuximab and other GD2-targeted therapies relies on the presence of the GD2 antigen on NB cells. Some NBs have been reported as GD2 low or negative, and such tumor cells could be nonresponsive to anti-GD2 therapy. As dinutuximab relies on complement and effector cells to mediate NB killing, factors affecting those components of patient response may also decrease dinutuximab effectiveness. This review summarizes the development of GD2 antibody-targeted therapy, the use of dinutuximab in both up-front and salvage therapy for high-risk NB, and the potential mechanisms of resistance to dinutuximab.
\end{abstract}

Keywords: neuroblastoma, GD2, immunotherapy, monoclonal antibody

\section{Introduction}

\section{Neuroblastoma (NB)}

NB is a malignant sympathetic nervous system tumor which accounts for $8 \%$ of childhood cancers. ${ }^{1}$ High-risk NB, defined primarily by age, stage, and MYCN oncogene amplification, poses a major therapeutic challenge. ${ }^{2}$ For high-risk NB, aggressive multi-agent therapy, myeloablative consolidation, followed by maintenance therapy with high-dose, pulse isotretinoin (13-cis-retinoic acid; 13-cis-RA) to treat minimal residual disease, improved event-free survival (EFS) if utilized before progressive disease. ${ }^{3,4}$ A further improvement in overall survival (OS) was seen with addition to maintenance therapy of the anti-GD2 antibody ch14.18 + cytokines. ${ }^{5}$ The latter study led to the Food and Drug Administration (FDA) granting a registered indication for the ch14.18 antibody (dinutuximab) when used as maintenance therapy for high-risk NB together with cytokines and 13-cis-RA after myeloablative therapy. A recent Children's Oncology Group (COG) randomized trial demonstrated a high response rate in NB 
patients with progressive disease for temozolomide (TMZ) + irinotecan (IRN) combined with dinutuximab. ${ }^{6}$

Anti-GD2 immunotherapy for NB has been previously reviewed. ${ }^{7-9}$ In this article, we review the development of dinutuximab and other antibodies targeting GD2, the widespread clinical use of dinutuximab as part of maintenance therapy for high-risk NB, and the emerging use of dinutuximab as a component of chemoimmunotherapy for treating NB patients with disease progression. We also briefly review recent studies addressing mechanisms of NB resistance to therapy with dinutuximab and novel alternative immunotherapy approaches for NB that are in preclinical and clinical development.

\section{GD2}

NBs contain large amounts of gangliosides, and the disialoganglioside GD2 is highly expressed in most NBs and is also expressed in other cancers including melanoma and osteogenic sarcoma. ${ }^{7}$ GD2 is synthesized ${ }^{10}$ starting with the conjugation of serine and palmitoyl-CoA into 3-ketosphinganine, which is reduced to sphinganine. Ceramide synthases convert sphinganine to dihydroceramide, which is reduced to ceramide, and is glycosylated to glucosylceramide and then to lactosylceramide. Lactosylceramide is converted to GM3 by GM3 synthase, GM3 to GD3 by GD3 synthase, and GM2/ GD2 synthase generates GD2 from GD3. Figure 1 illustrates the synthesis and metabolism of GD2.

\section{Antibodies to GD2}

Because of the strong expression of GD2 on NB, clinical grade antibodies were developed by multiple investigators. The different anti-GD2 antibodies and their key properties are listed in Table 1. Promising activity in early-phase clinical trials was seen with both a murine anti-GD2 antibody $(3 \mathrm{~F} 8)^{11,12}$ and a chimeric anti-GD2 antibody (ch14.18), ${ }^{10}$ with the latter being used for the COG pivotal trial of ch14.18+ cytokines + 13-cis-RA after myeloablative therapy. ${ }^{5}$ Humanized anti-GD2 antibodies ${ }^{13}$ and a humanized anti-GD2/ interleukin-2 (IL-2) fusion protein ${ }^{12,13}$ have also been studied in early-phase clinical trials. In the USA, ch14.18 (dinutuximab) has a registered indication for maintenance therapy of high-risk NB, ${ }^{14}$ and a biosimilar antibody produced in $\mathrm{CHO}$ cells (and thus with differing glycosylation) has European Medicines Agency (EMA) approval for NB maintenance therapy in Europe. ${ }^{15,16} \mathrm{GD} 2$ monoclonal antibodies have also been used for the detection and purging of NB cells in bone marrow and in peripheral blood stem cells. ${ }^{3,17,18}$

\section{Clinical trials with anti-GD2 antibodies and regulatory approvals}

Clinical trials of anti-GD2 antibodies have been conducted employing the antibodies as single agents or in combination with other chemotherapeutics or cytokines. It was apparent in the initial early-phase studies that the activity of anti-GD2 antibodies against NB tumor masses was limited. Thus, most of the early clinical trials focused on using the antibody as a component of maintenance therapy to eliminate MRD remaining after cytoreductive therapy with traditional cytotoxic chemotherapy and radiation. The murine anti-GD2 antibody $3 \mathrm{~F} 8$ was used alone in NB patients ${ }^{19}$ or with granulocyte-macrophage colony-stimulating factor (GM-CSF) to stimulate myeloid effector cells in mounting an antibodydependent cellular cytotoxicity (ADCC) attack on the tumor cells. ${ }^{20,21}$ In one Phase I study, the use of 3F8 alone induced major antitumor responses in four out of 17 patients with either melanoma or NB, with two of the responders being NB

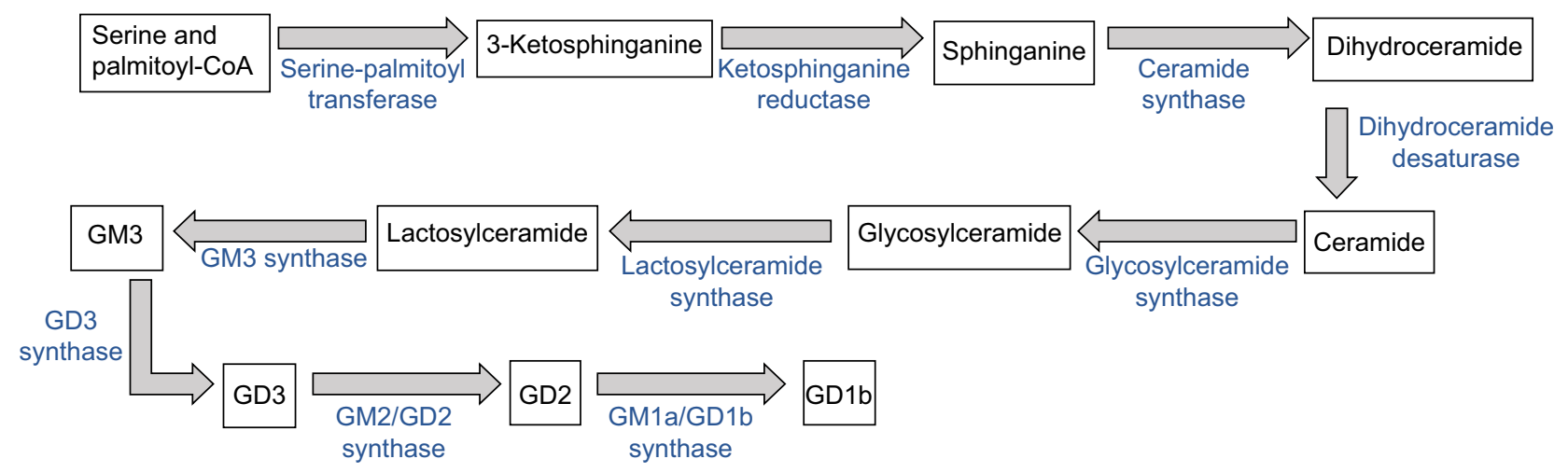

Figure I Synthesis and metabolism of GD2.

Notes: GD2 is synthesized via nine steps from ceramides (obtained likely preferentially via the de novo synthetic pathway). Ceramide is glycosylated, and then via additional steps GD2 is synthesized. GD2 can be metabolized to GDIb by GMIa/GDIb synthase. 
Table I Anti-GD2 antibodies

\begin{tabular}{|c|c|c|c|}
\hline Antibody & Description & Key aspects & References \\
\hline $3 F 8$ & Mouse lgG3 antibody & $\begin{array}{l}\text { Large experience as single agent and in } \\
\text { combinations }\end{array}$ & $11,12,21,22$ \\
\hline 126 & Mouse lgM & $\begin{array}{l}\text { Used to purge bone marrow and peripheral } \\
\text { blood stem cells }\end{array}$ & $17,18,27,104,132$ \\
\hline I4.G2a & Mouse $\lg G 2 a$ antibody & Used to generate chl4.18 & 39 \\
\hline ME36.I & Mouse antibody class switched to $\lg G I$ and $\lg G 2 a$ & Cross-reacts with GD3 & 7 \\
\hline 14.18 & Mouse lgG3 antibody & Lower ADCC than $14 . G 2 a$ & 39 \\
\hline L72 & Fully human IgM & Produced by EBV-transformed cell lines & 133 \\
\hline ch 14.18 (dinutuximab) & $\begin{array}{l}\text { Mouse human chimeric } \lg G \mid \text { antibody produced } \\
\text { in } S P 2 / 0\end{array}$ & FDA- and EMA-approved indication for NB & $5,12,14,134$ \\
\hline $\mathrm{ch} / 4.18 / \mathrm{CHO}$ & Mouse human chimeric antibody produced in & EMA-approved indication for NB & $15,32-34$ \\
\hline (dinutuximab beta) & $\mathrm{CHO}$ cells & & \\
\hline hul4.I8-IL2 & Humanized I4.I8 antibody fused with IL-2 & Clinical trials of fusion version with IL-2 & 48,50 \\
\hline hul $4.18 \mathrm{~K} 322 \mathrm{~A}$ & Point mutation made in hul 4.18 & Made to reduce complement activation & 13,38 \\
\hline hu3F8 & Humanized 3F8 antibody & Less complement activation than $3 \mathrm{~F} 8$ & 39, 135 \\
\hline $8 \mathrm{~B} 6$ & Monoclonal antibody that binds to $\mathrm{O}$-acetyl-GD2 & Proposed to reduce pain & 7,39 \\
\hline
\end{tabular}

Abbreviations: ADCC, antibody-dependent cellular cytotoxicity; EBV, Epstein-Barr Virus; EMA, European Medicines Agency; FDA, Food and Drug Administration; NB, neuroblastoma.

patients. ${ }^{19}$ When GM-CSF was combined with 3F8 in a Phase II NB trial, promising antitumor results were seen in patients with MRD in bone marrow. ${ }^{21}$ In a combined analysis of a series of nonrandomized single-arm trials for high-risk NB patients (NCI-V90-0023, NCT00002634, NCT00002560, NCT00072358), the best apparent outcome resulted from combining 3F8 with subcutaneous GM-CSF and 13-cis-RA. ${ }^{22}$ The murine anti-GD2 antibody (ch14.G2a) was combined with intravenous IL-2 in a Phase I/IB trial (CCG-0901) and showed a partial response in one NB patient out of 33 patients with GD2-positive malignances and a decrease in NB cells in the bone marrow of three patients. ${ }^{23}$

Humanization of anti-GD2 antibodies was undertaken to diminish the development of human anti-mouse antibodies (HAMAs) which can potentially block antitumor activity of anti-GD2 antibodies. The first such antibody was not totally humanized but is the chimeric 14.18 (ch14.18) which was developed from 14.G2a. Clinical trials (A0935A, ANBL0931, CCG-0935) of ch14.18 combined with GM-CSF, IL-2, and 13-cis-CA demonstrated the combination to be well tolerated and showed promising results. ${ }^{24-27}$ The COG undertook a large prospective randomized trial (ANBL0032) to determine whether adding ch14.18 combined with GM-CSF and IL-2 to maintenance therapy with 13-cis-RA (given after the completion of induction chemotherapy and myeloablative chemotherapy) was superior to maintenance with 13-cis-RA alone. ${ }^{5}$ The $\mathrm{COG}$ randomized trial demonstrated a significant improvement in both EFS and OS for patients randomized to receive ch14.18 + GM-CSF + IL-2 (intravenous)+13-cis-RA compared to maintenance therapy with 13 -cis-RA alone. ${ }^{5}$
Monitoring of that randomized trial (blinded to investigators) revealed that the stopping rule for the demonstration of effectiveness had been achieved prior to completion of planned enrollment; therefore, the study was converted to a nonrandomized study where all patients received maintenance with ch14.18 + cytokines + 13-cis-RA. To obtain additional data on safety and toxicity required by the FDA for the registration of ch14.18, a nonrandomized Phase III study (ANBL0931) of ch14.18 + GM-CSF + IL-2 +13-cis-RA was carried out, which demonstrated safety, toxicity, and outcome data comparable to that observed in the ANBL0032 study. ${ }^{25}$ United Therapeutics Corporation, Silver Spring, MD, USA obtained a license from the National Cancer Institute for ch14.18, established production of the antibody, and secured from the FDA, a registered indication for the use of ch14.18 (now called dinutuximab) in combination with GM-CSF + IL-2 + 13-cis-RA for maintenance therapy of high-risk NB.

A biosimilar version of the chimeric ch14.18 antibody known as ch14.18/CHO and also as dinutuximab beta was developed by European investigators to be produced in $\mathrm{CHO}$ cells; this latter antibody having an altered glycosylation pattern compared to ch 14.18 produced in SP2/0 cells. ${ }^{7,15,28,29}$ ch14.18/CHO was found to have similar pharmacokinetics to ch14.18 and showed a partial response in two out of seven patients with residual disease. ${ }^{15}$ Although not a randomized study, maintenance with ch14.18/CHO + IL-2 + 13-cis-RA (without GM-CSF) showed a significantly better outcome for patients receiving ch14.18/CHO + IL-2 + 13-cis-RA compared to historical controls before immunotherapy. ${ }^{30}$ A study (EudraCT number 2005-001267-63) showed that 
ch14.18/CHO was also found to be effective at stimulating effector responses throughout the treatment period when used as a continual long-term infusion with subcutaneous IL-2. ${ }^{31}$ The long-term infusion of dinutuximab beta resulted in reduced pain. ${ }^{32,33}$ Dinutuximab beta (ch14.18/CHO) has an approved indication in the European Union (EU) for treating high-risk NB patients at 12 months and greater who have received at least a partial response to induction chemotherapy and have received myeloablative chemotherapy. ${ }^{34,35}$ Dinutuximab, combined with IL-2, has an EMA-registered indication for the treatment of NB patients with relapsed or refractory disease who have not achieved a complete response to the first-line therapy after disease is stabilized. ${ }^{35}$

\section{Relative contributions of multi-agent NB maintenance therapy}

As the COG ANBL0032 randomized Phase III clinical trial employed ch14.18 together with GM-CSF and IL-2 and interspersed with 13-cis-RA, the relative contribution of the various components of maintenance therapy could not be determined from that trial. Although only randomized trials testing the various components (which are likely not feasible) can truly define relative contributions, some studies provide data that support the value of all components of therapy used for maintenance as used in the ANBL0032 study. For example, a nonrandomized study of ch14.18 given as a single agent without cytokines or 13-cis-RA in 334 metastatic NB patients (Cooperative German NB trials NB90 and NB97) did not show a significant improvement in patient outcome compared to maintenance cytotoxic chemotherapy. ${ }^{36}$ As described earlier, comparisons of studies using the murine anti-GD2 antibody 3F8 alone and with GM-CSF showed a better outcome for patients treated with $3 \mathrm{~F} 8$ combined with GM-CSF. $^{22}$ Pharmacokinetic analyses of 13-cis-RA for 524 patients treated on ANBL0032 with ch14.18 + cytokines + 13-cis-RA showed a lower OS for patients aged $>18$ months at diagnosis who achieved low exposures of 13-cis-RA and its active metabolite, suggesting an independent contribution of 13-cis-RA to maintenance therapy with ch14.18+ cytokines. $^{37}$

\section{Alterations of anti-GD2 antibodies to decrease systemic toxicity}

A major toxicity of anti-GD2 antibody infusions is neuropathic pain, which is thought to be a result of complement activation at GD2-expressing nerve fibers. ${ }^{38}$ Humanized anti-GD2 antibodies have shown some reduction in pain, with hu3F8 resulting in less apparent pain than murine $3 \mathrm{~F} 8 .{ }^{39}$ For hu14.18, a point mutation to reduce complement activation was made to create hu14.18K $322 \mathrm{~A} .{ }^{38}$ In a Phase I study (NCT0074349) in recurrent or refractory NB, hu14.18K322A treatment resulted in four out of 31 complete responses and two out of 31 partial responses, but pain was still a common side effect. ${ }^{40}$ A pilot study (NCT01576692) in recurrent/ refractory NB with hu14.18K322A combined with GM-CSF and subcutaneous IL-2 resulted in a $61.5 \%$ response rate, with four complete responses and four partial responses. ${ }^{13}$ Thus, the elimination of complement binding may maintain antiGD2 activity and diminish neuropathic pain, but whether or not antitumor activity at the level obtained with dinutuximab remains can only be determined in a randomized clinical trial.

\section{Anti-GD2 immunocytokines}

Immunocytokines are created by fusing a cytokine to an antibody. IL-2 was fused directly to ch14.18 to make a GD2specific immunocytokine, and IL-15 was directly fused to the anti-GD2 antibody c.60C3. ${ }^{41-44}$ The direct association of the cytokine with the antibody was hypothesized to be more effective by concentrating the cytokine to the tumor cells. ${ }^{7}$ In mouse models, the immunocytokine of ch14.18-IL-2 was shown to have superior antitumor activity compared to ch14.18 or IL-2 separately. ${ }^{9,45-47}$ In human studies, hu14.18 was used to create an IL-2 immunocytokine in an effort to avoid human anti-chimeric antibodies (HACAs). ${ }^{48}$ However, initial Phase I studies (NCT00003750) did not show any objective clinical responses with hu14.18-IL-2. ${ }^{49}$ In a Phase II study (NCT00082758) using hu14.18-IL-2, five patients out of 23 had complete repsonses. ${ }^{48,50}$ In these clinical trials, hu14.18-IL-2 was well tolerated and demonstrated activity against recurrent $\mathrm{NBs}$, but whether the immunocytokine offers advantages over dinutuximab combined with cytokines remains unclear. ${ }^{7,50}$

\section{Use of dinutuximab to treat progressive NB}

To address the potential for dinutuximab to enhance salvage chemotherapy of recurrent NB, a COG "pick-the-winner" randomized trial was carried out testing the addition of two novel agents (dinutuximab + GM-CSF vs temsirolimus) to TMZ + IRN (commonly used for re-induction chemotherapy of NB). That Phase II study showed a higher response rate in the arm of the trial where patients received TMZ + IRN + dinutuximab and has led to an increasingly frequent use of the latter combination for treating recurrent NB. TMZ + IRN + dinutuximab + GM-CSF, achieved 10 partial responses and 11 complete responses for an overall $53 \%$ objective response 
rate (ANBL1221); with the study of additional patients, the objective response rate was $\sim 40 \% .^{6,51}$ Future COG Phase II studies are planned that will build on the combination of $\mathrm{TMZ}+\mathrm{IRN}+$ dinutuximab. In spite of the exciting clinical activity of TMZ + IRN + dinutuximab, more than half of all patients treated with that regimen did not show an objective response. There is currently no means for identifying patients who will not respond to TMZ + IRN + dinutuximab. A Phase I trial (NCT01711554) combining ch14.18 with lenalidomide and 13-cis-RA showed promising initial results, suggesting that immune cell activators other than cytokines may be effective in combination with dinutuximab, but whether such approaches are more effective (or as effective and better tolerated) than antibody + cytokines remains to be determined. ${ }^{52}$

\section{Potential mechanisms of resistance to dinutuximab: differing immune effector cells}

Progressive disease during or after therapy with dinutuximab reflects either inadequate exposure of tumor cells to the antibody, the inability of the patient's immune effectors (myeloid cells, natural killer [NK] cells, complement) to combine with the antibody to kill tumor cells, or resistance of NB cells to antibody therapy. Mechanisms of resistance to anti-GD2 antibody therapy are not well defined. Most efforts in understanding the mechanisms of treatment failure of dinutuximab when used to treat MRD have focused on studying effector cells involved in ADCC. ${ }^{15,16,19-21}$ Studies seeking to improve therapy have largely focused on improving the delivery of cytokines (such as with an immunocytokine) ) $^{22}$ or using approaches to enhance the activity of effector cells..$^{53,54}$

The anti-cancer activity of dinutuximab relies on parterning with components of the patient's immune response mechanisms that are listed in Table 2. One key player in the antitumor response of dinutuximab is NK cells. These cells are capable of killing antibody-bound NB cells via ADCC. The importance of NK cells in NB treatment has been widely reported. ${ }^{55-60}$ However, the low expression of NK cell-activating ligands, such as Major histocompatibility complex (MHC) class I related chain A, can compromise the ability of NK cells to target NB. ${ }^{59,61,62}$ Furthermore, TGF $\beta 1$ in the tumor microenvironment can inhibit NK cell cytotoxicity, which can be restored by treatment with the TGF $\beta R 1$ inhibitor galunisertib. ${ }^{53}$ The addition of cytokines to activate NK cells or other immune cells in the tumor microenvironment is one way to stimulate $\mathrm{ADCC}$ in antibody-treated tumors. The addition of GM-CSF and IL-2 to anti-GD2 therapy enhanced ADCC against NB. ${ }^{5,22,23,50,63-66}$ GM-CSF increases the activation of myeloid cells, which are also important in antibodymediated antitumor responses..$^{22,66-68}$

Another complicating factor in the NK cell-mediated antitumor response is the repertoire of killer cell immunoglobulin-like receptors (KIRs) and KIR ligands expressed in NB patients. The balance between activating and inhibitory KIR signals influences NK cell activation. NK cells that have mismatched KIR/KIR ligands have been reported as playing a key role in 3F8 and hu14.18-IL-2-mediated anti-NB responses. ${ }^{22,59,66,69,70} \mathrm{COG}$ investigators examined KIR and KIR ligand genotypes in patients in the ANBL0032 Phase III trial randomized to dinutuximab, IL-2, GM-CSF, and isotretinoin vs patients randomized to only isotretinoin. The immunotherapy group had a significantly better outcome than those randomized to only isotretinoin for the patients with all KIR ligands detected. However, if the patients had the KIR ligand missing genotype, no improvement in outcome was seen for those randomized to immunotherapy. ${ }^{71}$ Similarly, patients randomized to immunotherapy had a better outcome than isotretinoin alone depending on their KIR2DL2/KIR ligand status. ${ }^{71}$ In a subsequent study, the presence of $\mathrm{NKp}^{+}$, $\mathrm{KIR}^{+}$, and $\mathrm{KLRB}^{+}$in pretreatment NK cells correlated with increased EFS and OS in patients treated with dinutuximab, GM-CSF, IL-2, and isotretinoin. ${ }^{72}$ Thus, it is possible that patients with certain immune effector cell genotypes may not benefit from antibody therapy, but further studies are needed to determine whether such genotypes are a robust way of identifying patients who do not benefit from anti-GD2 antibody therapy.

Table 2 Effector cells involved in dinutuximab treatment

\begin{tabular}{|c|c|c|}
\hline Effector mechanism & Positive features & Negative features \\
\hline NK cells & ADCC; activation can be enhanced with cytokines $5,22,23,50,63-66$ & $\begin{array}{l}\text { KIR ligands being present may inhibit } \\
A D C C^{22,59,66,69,70}\end{array}$ \\
\hline Neutrophils & ADCC; response enhanced by chemotherapy ${ }^{83}$ & Diminished with cytotoxic chemotherapy \\
\hline Macrophages & ADCC/phagocytosis of tumor ${ }^{67,79,80}$ & TAMs are associated with poor prognosis ${ }^{75-78}$ \\
\hline$\gamma \delta \mathrm{T}$ cells & Tumor cytotoxicity when combined with $\mathrm{TMZ}^{87}$ & Minor cell population/may require ex vivo prep ${ }^{84,136}$ \\
\hline Complement & CDC & Complement binding associated with pain ${ }^{75-78}$ \\
\hline
\end{tabular}

Abbreviations: ADCC, antibody-dependent cellular cytotoxicity; CDC, complement-dependent cytotoxicity; KIR, immunoglobulin-like receptor; NK, natural killer; TAMs, tumor-associated macrophages; TMZ, temozolomide. 
FC gamma receptors (FCGRs) on effector cells are necessary to attach antibodies and to mediate ADCC activity. In addition to KIR ligand mismatch, FCGR3A and FCGR2A polymorphisms have been associated with better outcome in antibody-treated NB patients. ${ }^{68,73}$ FCGR3A is predominantly on NK cells. ${ }^{68,74}$ FCGR2A is primarily expressed on macrophages, neutrophils, and monocytes, suggesting a role for enhanced phagocyte-mediated ADCC in 3F8 and ch14.18/ CHO-treated NB cells. ${ }^{68,73}$ Furthermore, Siebert et al ${ }^{68}$ also found that ch14.18/CHO-treated patients with FCGR2A and FCGR3A polymorphisms and the activating KIR 2DS2 had the best antitumor activity.

As reflected in the data with FCGR2A polymorphisms, NK cells are not the only effector cells that are responsible for antitumor responses in antibody-treated tumors (Table 2). Macrophages and neutrophils are also capable of ADCC. Tumor-associated macrophages (TAMs) have been identified in NB tumors and have generally been associated with poor prognosis. ${ }^{75-78}$ However, macrophages are also able to phagocytose NB tumors and participate in an antitumor response. ${ }^{67,79,80}$ Macrophage polarization, and subsequent response to NB, relies in part on the cytokines and other factors in the tumor microenvironment. Neutrophil-mediated ADCC against NB has previously been reported. ${ }^{81,82}$ Furthermore, neutrophil-mediated antitumor responses in vitro were found to be associated with GD2 expression on NB cell lines treated with dinutuximab. ${ }^{83}$ Treatment with chemotherapy followed by dinutuximab also enhanced neutrophil-mediated cytotoxicity. ${ }^{83}$

A third cell type that induces tumor cell death is $\gamma \delta \mathrm{T}$ cells. These cells have been expanded and used to treat NB. ${ }^{84,85} \mathrm{~A}$ lineage of $\gamma \delta \mathrm{T}$ cells, $\mathrm{V} \gamma 9 \mathrm{~V} \delta 2$ cells, was shown to have cytotoxic activity against NB cells treated with ch14.18 in vitro. ${ }^{86}$ An in vivo mouse study demonstrated that administered $\gamma \delta$ $\mathrm{T}$ cells in combination with dinutuximab and TMZ resulted in tumor regression. ${ }^{87}$

\section{Potential mechanisms of resistance to dinutuximab: antibodies to the antibody}

Treating NB patients with antibody therapy can lead to the development of antidrug antibodies (ADAs). For murine antibodies, such as 3F8, HAMAs have been reported in patients. The presence of HAMA not only led to faster clearance of antibodies but also was associated with better OS in 3F8-treated patients. ${ }^{22,88-90}$ Patients treated with ch14.18/CHO have generated HACAs. The development of HACA was associated with lower levels of therapeutic antibody detected and lower levels of ADCC and complement-dependent cytotoxicity (CDC). ${ }^{31}$ However, the serum from NB patients treated with ch14.18/CHO who developed HACA still had measurable $\mathrm{CDC}$ at the first treatment cycle and subsequent cycles. ${ }^{91}$ The frequency of HACA in patients treated with ch14.18/CHO (21\%) was similar to those treated with dinutuximab. ${ }^{31,92} \mathrm{In}$ patients treated with humanized anti-GD2 antibodies, about $40 \%$ developed human antihuman antibodies (HAHAs) to hu14.18K322A, while $21 \%$ of patients were reported to develop an HAHA response to hu3F8 ${ }^{40,93}$ Similar to what was seen in ch14.18/CHO, HAHA in hu3F8 was associated with lower serum levels of antibody in NB patients..$^{93}$ The effect of ADA on patient response in anti-GD2 antibody therapy is still not fully understood and requires further investigation. Furthermore, the generation of an anti-idiotype response to GD2 antibodies may actually enhance antitumor activity, although further investigation is also needed in this area. ${ }^{91,94}$

\section{Potential mechanisms of resistance to dinutuximab: low GD2 expression}

Prior data in the literature show that most NBs at diagnosis express GD2 and GD2 negativity in tumors recurring after GD2 therapy was thought to be infrequent. ${ }^{89}$ However, a recently published study by Schumacher-Kuckelkorn et a ${ }^{95}$ in Germany demonstrated that low GD2-expressing NBs do occur, perhaps in as high as $12 \%$ of patients. The number of patients who had been treated with GD2 antibody therapy was not clear, and prior anti-GD2 therapy could increase the proportion of GD2-low patients. ${ }^{95}$ In a study of NB patients treated with ch14.18, five out of 15 patients experienced treatment failure and also had significantly lower GD2 expression than the patients without relapse. ${ }^{96}$ These results show the association of a low percentage of GD2-positive cells prior to treatment corresponded to relapse in patients treated with ch14.18. ${ }^{96} \mathrm{~A}$ recent study by COG investigators also demonstrated low dinutuximab binding to NB cell lines and patientderived xenografts (PDXs), using multicolor flow cytometry in patient blood and bone marrow samples. ${ }^{97}$ Thus, low or negative GD2 expression may account for some treatment failures in NB patients treated with dinutuximab (Figure 2). Importantly, these latter data suggest that not all patients with progressive NB will have tumor cells expressing high amounts of GD2 and such patients may experience toxicity without benefit from dinutuximab in salvage regimens. It is possible that patients who benefit from dinutuximab are those with a high density and/or a high percentage of cells that are GD2 positive. However, there exist no nonclinical or clinical data defining the levels of GD2 expression that are needed to trigger antitumor responses. The selective pressure of dinutuximab therapy may result in decreased GD2 expression, 


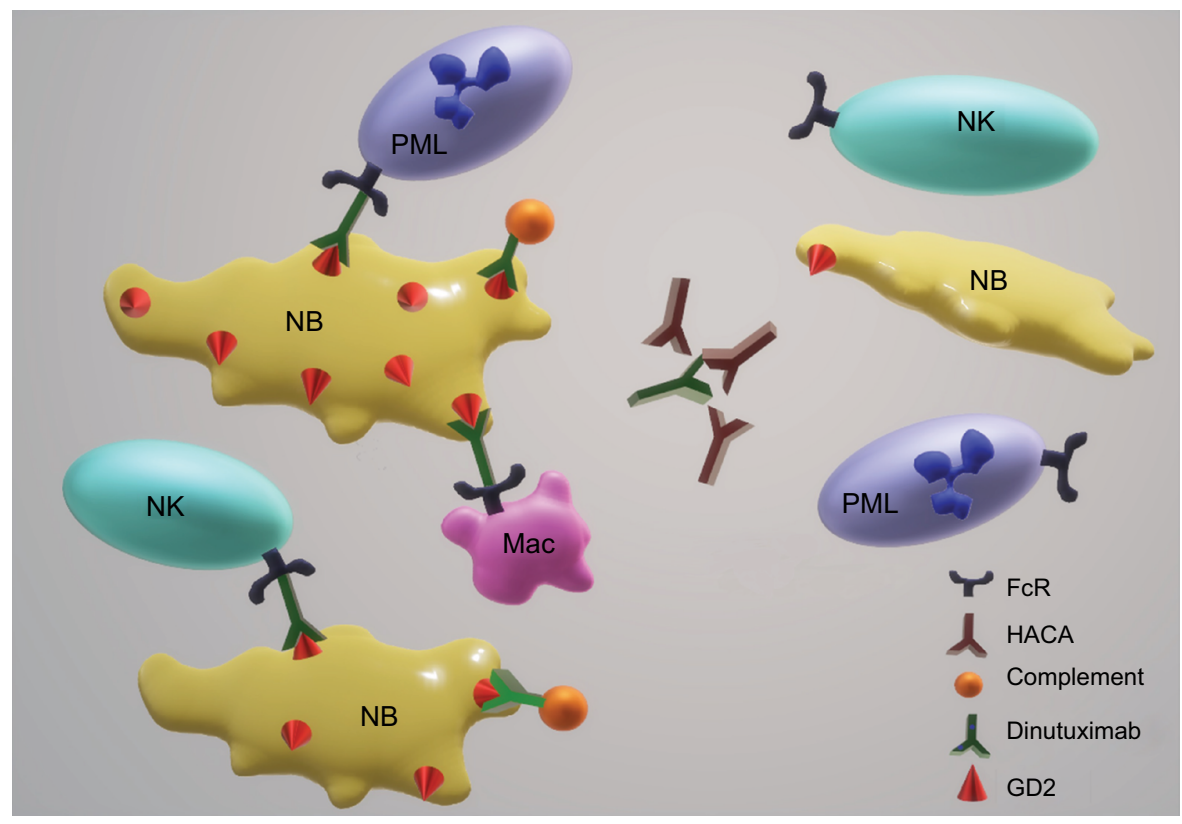

Figure 2 Potential mechanisms of acquired NB resistance to dinutuximab.

Notes: Killing of NB cells by dinutuximab requires the antibody to partner with the effector cells, such as NK cells, neutrophils (PMLs), and Mac to kill via ADCC and/or to fix complement on the tumor cell membrane. Based on the data to date, potential mechanisms of acquired resistance to dinutuximab are illustrated and include neutralization of antibody with HACAs and decreased expression or exposure on the cell surface of GD2.

Abbreviations: ADCC, antibody-dependent cellular cytotoxicity; HACAs, human anti-chimeric antibodies; Mac, macrophages; NK, natural killer; NB, neuroblastoma; PMLs, polymorphonuclear leukocytes.

which has been observed with targeting CD20 on lymphoma with rituximab, ${ }^{98-101}$ targeting CD19 on leukemia with CAR $\mathrm{T}$ cells, ${ }^{102}$ and with antibodies to EGF in breast cancer. ${ }^{103}$

\section{NB antibodies against antigens other than GD2}

A number of different monoclonal antibodies that recognize cell surface antigens on NB have been described. HSAN1.2, 459, and 390 are antibodies specific to NB but not bone marrow and were used for the purging of NB from bone marrow. ${ }^{3,17,18,104-107}$ KP-NAC8 is a monoclonal antibody specific to the cell surface of NB cells. ${ }^{108} \mathrm{~B} 7-\mathrm{H} 3$ (CD276) is found on the NB cell surface and can be targeted with antibodies, including enoblituzumab (MGA271) and 8H9. ${ }^{109-117}$ More recently, GPC2 has been identified as a potential target for drug antibody conjugates on the surface of NB cells. ${ }^{118-120}$ Because of the potential for resistance to dinutuximab resulting from decreased GD2 expression, such antibodies have potential for treating recurrent NBs and for eventually being combined with dinutuximab for initial therapy.

\section{Targeting GD2 with non-antibody approaches}

The success in acute lymphoblastic leukemia with chimeric antigen receptor T cells (CART) against CD19 ${ }^{121-123}$ has led to a number of investigators developing CART targeting GD2. ${ }^{124-128}$ While some activity has been observed in NB clinical trials with GD2-CART, activity data that would support CART being tested in large randomized trials have not yet been achieved.

With the goal of providing a long-term immunological attack against NB, investigators have developed vaccine approaches with various antigens, including GD2. While there are potential advantages to a vaccine approach or to the use of CART in treating NB, a major drawback is that the vast majority of high-risk NB patients in the USA and EU receive dinutuximab maintenance therapy as part of up-front therapy. If, as indicated by some data, resistance to NB involves a decreased expression of GD2, then both GD2 vaccine and CART approaches will not be effective against tumor cells escaping primary therapy.

\section{Conclusions}

Monoclonal antibodies to GD2, murine, chimeric, and humanized have all shown activity. The clinical data suggested that optimal use of antibody therapy as maintenance therapy to eliminate MRD remaining after maximal cytotoxic therapy, which required randomized clinical trials to prove effectiveness of adding anti-GD2 therapy to standard-of-care approaches. A Phase III randomized trial of dinutuximab 
conclusively demonstrated that adding dinutuximab + GMCSF + IL-2 to maintenance therapy with 13-cis-RA significantly improved outcome. ${ }^{5}$ Results with other anti-GD2 antibodies, although not tested in a randomized fashion, are similar. Regulatory approval has been achieved for dinutuximab in the USA and the EU and for the biosimilar ch14.18/ CHO (dinutuximab beta) antibody in the EU.

The use of cytokines with dinutuximab has been developed to enhance the innate immune response, which is especially important in previously treated NB patients whose adaptive immune system has been inhibited. ${ }^{7}$ It is still an area of ongoing research to determine which immune effector cells are responsible for the antitumor responses with dinutuximab. NK cells, complement, and macrophages have been associated with enhanced antitumor activity through ADCC, CDC, and other mechanisms in antibody-treated NB. ${ }^{7,59,129,130}$ Neutrophils have also been reported to play a role in being responsible for killing tumor cells treated with dinutuximab, especially in combination with chemotherapy. ${ }^{81,83}$

Success with dinutuximab in maintenance therapy for patients in first response led to exploring the combination of dinutuximab with chemotherapeutic agents. Data from a study treating patients with progressive disease with the combination of TMZ + IRN + dinutuximab + GM-CSF showed a very promising response rate, ${ }^{6,51}$ and recent nonclinical data demonstrated a significant contribution of dinutuximab to the combination of TMZ + IRN + dinutuximab in NB PDXs. ${ }^{97}$ Dinutuximab has been shown to be more efficient for targeting NB cells in bone marrow rather than solid tumor mass disease, ${ }^{7,39}$ which may impact which patients achieve response when treating overt progressive disease. As low GD2-expressing NBs do not show a response to dinutuximab in PDX models, ${ }^{97}$ testing patients for tumor cell GD2 expression, together with other biomarkers, such as KIR mismatch, may identify patients likely not to benefit from dinutuximab therapy.

Because of the success in combining dinutuximab with cytotoxic chemotherapy in the relapse setting, ongoing and planned studies seek to incorporate dinutuximab into induction chemotherapy for NB. ${ }^{131}$ Although this may enhance the effectiveness of induction chemotherapy, such an approach has the potential to provide additional selection pressure against GD2 expression and may enhance the frequency of low GD2-expressing tumor cells, which could diminish the effectiveness of maintenance therapy and of treating patients with progressive disease with anti-GD2 antibodies. Thus, if the use of dinutuximab occurs in all phases of therapy for high-risk NB, it will be increasingly important to assess
GD2 expression in tumor cells as part of clinical trials and potentially in the future as a guide to therapy. For patients with low GD2-expressing tumors, the use of therapeutic antibodies against non-GD2 antigens, such as B7-H3, offers the potential for activity in the setting of progressive disease and eventually for use in multi-antibody combination therapy approaches. ${ }^{109-111}$

\section{Disclosure}

Dr Michelle E Keyel reports grants from United Therapeutics, during the conduct of the study; Dr C Patrick Reynolds reports grants and non-financial support from United Therapeutics, during the conduct of the study. The authors report no other conflicts of interest in this work.

\section{References}

1. Reynolds CP, Seeger RC. Neuroblastoma. In: Haskell CM, editor. Cancer Treatment. 5th ed. Philadelphia: W.B. Saunders; 2000:1214-1236.

2. Park JR, Bagatell R, London WB, et al; COG Neuroblastoma Committee. Children's Oncology Group's 2013 blueprint for research: neuroblastoma. Pediatr Blood Cancer. 2013;60(6):985-993.

3. Matthay KK, Villablanca JG, Seeger RC, et al. Treatment of high-risk neuroblastoma with intensive chemotherapy, radiotherapy, autologous bone marrow transplantation, and 13-cis-retinoic acid. Children's Cancer Group. N Engl J Med. 1999;341(16):1165-1173.

4. Matthay KK, Reynolds CP, Seeger RC, et al. Long-term results for children with high-risk neuroblastoma treated on a randomized trial of myeloablative therapy followed by 13-cis-retinoic acid: a children's oncology group study. J Clin Oncol. 2009;27(7):1007-1013.

5. Yu AL, Gilman AL, Ozkaynak MF, et al; Children's Oncology Group. Anti-GD2 antibody with GM-CSF, interleukin-2, and isotretinoin for neuroblastoma. N Engl J Med. 2010;363(14):1324-1334.

6. Mody R, Naranjo A, Van Ryn C, et al. Irinotecan-temozolomide with temsirolimus or dinutuximab in children with refractory or relapsed neuroblastoma (COG ANBL1221): an open-label, randomised, phase 2 trial. Lancet Oncol. 2017;18(7):946-957.

7. Dobrenkov K, Cheung NK. GD2-targeted immunotherapy and radioimmunotherapy. Semin Oncol. 2014;41(5):589-612.

8. Matthay KK, George RE, Yu AL, Al Y. Promising therapeutic targets in neuroblastoma. Clin Cancer Res. 2012;18(10):2740-2753.

9. Perez Horta Z, Goldberg JL, Sondel PM. Anti-GD2 mAbs and nextgeneration $\mathrm{mAb}$-based agents for cancer therapy. Immunotherapy. 2016;8(9):1097-1117.

10. Berois N, Osinaga E. Glycobiology of neuroblastoma: impact on tumor behavior, prognosis, and therapeutic strategies. Front Oncol. 2014;4:114.

11. Kailayangiri S, Altvater B, Meltzer J, et al. The ganglioside antigen G(D2) is surface-expressed in Ewing sarcoma and allows for MHCindependent immune targeting. Br JCancer. 2012;106(6):1123-1133.

12. Cheung NK, Neely JE, Landmeier B, Nelson D, Miraldi F. Targeting of ganglioside GD2 monoclonal antibody to neuroblastoma. $J$ Nucl Med. 1987;28(10):1577-1583.

13. Federico SM, McCarville MB, Shulkin BL, et al. A Pilot Trial of Humanized Anti-GD2 Monoclonal Antibody (hu14.18K322A) with Chemotherapy and Natural Killer Cells in Children with Recurrent/ Refractory Neuroblastoma. Clin Cancer Res. 2017;23(21):6441-6449.

14. Dhillon S. Dinutuximab: first global approval. Drugs. 2015;75(8): 923-927.

15. Ladenstein R, Weixler S, Baykan B, et al. Ch14.18 antibody produced in $\mathrm{CHO}$ cells in relapsed or refractory Stage 4 neuroblastoma patients: a SIOPEN Phase 1 study. MAbs. 2013;5(5):801-809. 
16. Mueller I, Ehlert K, Endres S, et al. Tolerability, response and outcome of high-risk neuroblastoma patients treated with long-term infusion of anti-GD antibody ch14.18/CHO. MAbs. 2018;10(1):55-61.

17. Kreissman SG, Seeger RC, Matthay KK, et al. Purged versus nonpurged peripheral blood stem-cell transplantation for high-risk neuroblastoma (COG A3973): a randomised phase 3 trial. Lancet Oncol. 2013;14(10):999-1008

18. Reynolds CP, Seeger RC, Vo DD, Black AT, Wells J, Ugelstad J. Model system for removing neuroblastoma cells from bone marrow using monoclonal antibodies and magnetic immunobeads. Cancer Res. 1986;46(11):5882-5886.

19. Cheung NK, Lazarus H, Miraldi FD, et al. Ganglioside GD2 specific monoclonal antibody 3F8: a phase I study in patients with neuroblastoma and malignant melanoma. J Clin Oncol. 1987;5(9):1430-1440.

20. Kushner BH, Cheung NK. GM-CSF enhances 3F8 monoclonal antibody-dependent cellular cytotoxicity against human melanoma and neuroblastoma. Blood. 1989;73(7):1936-1941.

21. Kushner BH, Kramer K, Cheung NK. Phase II trial of the anti-G(D2) monoclonal antibody $3 \mathrm{~F} 8$ and granulocyte-macrophage colony-stimulating factor for neuroblastoma. J Clin Oncol. 2001;19(22):4189-4194.

22. Cheung NK, Cheung IY, Kushner BH, et al. Murine anti-GD2 monoclonal antibody 3F8 combined with granulocyte-macrophage colony-stimulating factor and 13-cis-retinoic acid in high-risk patients with stage 4 neuroblastoma in first remission. J Clin Oncol. 2012;30(26):3264-3270.

23. Frost JD, Hank JA, Reaman GH, et al. A phase I/IB trial of murine monoclonal anti-GD2 antibody 14.G2a plus interleukin-2 in children with refractory neuroblastoma: a report of the Children's Cancer Group. Cancer. 1997;80(2):317-333.

24. Gilman AL, Ozkaynak MF, Matthay KK, et al. Phase I study of ch14.18 with granulocyte-macrophage colony-stimulating factor and interleukin-2 in children with neuroblastoma after autologous bone marrow transplantation or stem-cell rescue: a report from the Children's Oncology Group. J Clin Oncol. 2009;27(1):85-91.

25. Ozkaynak MF, Gilman AL, London WB, et al. A Comprehensive Safety Trial of Chimeric Antibody 14.18 With GM-CSF, IL-2, and Isotretinoin in High-Risk Neuroblastoma Patients Following Myeloablative Therapy: Children's Oncology Group Study ANBL0931. Front Immunol. 2018;9:1355

26. Al Y, Alvarado C, Rao VJ, Castleberry RP. Usefulness of a chimeric anti-GD2 (ch14.18) and GM-CSF for refractory neuroblastoma: a POG phase II study. Proc Am Soc Clin Oncol. 1997;16:1846.

27. Ozkaynak MF, Sondel PM, Krailo MD, et al. Phase I study of chimeric human/murine anti-ganglioside G(D2) monoclonal antibody (ch14.18) with granulocyte-macrophage colony-stimulating factor in children with neuroblastoma immediately after hematopoietic stemcell transplantation: a Children's Cancer Group Study. J Clin Oncol. 2000;18(24):4077-4085.

28. Borys MC, Dalal NG, Abu-Absi NR, et al. Effects of culture conditions on N-glycolylneuraminic acid (Neu5Gc) content of a recombinant fusion protein produced in $\mathrm{CHO}$ cells. Biotechnol Bioeng. 2010;105(6):1048-1057.

29. Loibner H, Schuster M, Mutschlechner O, et al. Lack of alpha-gal glycosylation determinants expressed on antibody ch14.18 produced in Chinese Hamster Ovary (CHO) cells (APN311) Comparison to a ch14.18 variant produced in murine SP2/0 cells. Abstract presented at: Conference: International Society of Paediatric Oncology Europe; October, 2014; Vienna, Austria. Available from: https:// www.researchgate.net/publication/275887484_Lack_of_alpha gal_glycosylation_determinants_expressed_on_antibody_ch1418_ produced_in_Chinese_Hamster_Ovary_CHO_cells_APN311_Comparison_to_a_ch1418_variant_produced_in_murine_SP20_cells. Accessed December 19, 2018.

30. Ladenstein R, Pötschger U, Valteau-Couanet D. Immunotherapy with Anti-GD2 Antibody ch14.18/CHO \pm IL2 Within The HR-NBL1/SIOPEN Trial Improves Outcome of High-Risk Neuroblastoma Patients Compared to Historical Controls. Abstract presented at: Advances in Neuroblastoma Research; May 9-12, 2018; San Francisco, CA, USA
31. Siebert N, Eger C, Seidel D, et al. Pharmacokinetics and pharmacodynamics of ch14.18/CHO in relapsed/refractory high-risk neuroblastoma patients treated by long-term infusion in combination with IL-2. MAbs. 2016;8(3):604-616.

32. Siebert N, Troschke-Meurer S, Marx M, et al. Impact of HACA on Immunomodulation and Treatment Toxicity Following ch14.18/CHO Long-Term Infusion with Interleukin-2: Results from a SIOPEN Phase 2 Trial. Cancers. 2018;10(10):387.

33. Ceylan K, Jahns LJ, Lode BN, et al. Inflammatory response and treatment tolerance of long-term infusion of the anti-GD antibody ch14.18/CHO in combination with interleukin-2 in patients with high-risk neuroblastoma. Pediatr Blood Cancer. 2018;65(6): e26967.

34. Dinutuximab beta for the Treatment of Neuroblastoma. Drug Development Technology; 2017. Available from: www.drugdevelopment-technology.com/projects/dinutuximab-beta-for-the-treatmentof-neuroblastoma/. Accessed October 31, 2018.

35. Qarziba (previously Dinutuximab beta EUSA and Dinutuximab beta Apeiron). European Medicines Agency; 2018. Available from: www.ema.europa.eu/en/medicines/human/EPAR/qarziba-previouslydinutuximab-beta-eusa-dinutuximab-beta-apeiron. Accessed October 23, 2018

36. Simon T, Hero B, Faldum A, et al. Consolidation treatment with chimeric anti-GD2-antibody ch14.18 in children older than 1 year with metastatic neuroblastoma. J Clin Oncol. 2004;22(17): 3549-3557.

37. Cho H, Yang S, Sonawane P, et al. Pharmacokinetics (PK) of 13-cisretinoic acid in COG Phase III neuroblastoma studies. Abstract presented at: Advances in Neuroblastoma Research; May 9-12, 2018; San Francisco; CA, USA.

38. Sorkin LS, Otto M, Baldwin WM, et al. Anti-GD(2) with an FC point mutation reduces complement fixation and decreases antibody-induced allodynia. Pain. 2010;149(1):135-142.

39. Ahmed M, Cheung NK. Engineering anti-GD2 monoclonal antibodies for cancer immunotherapy. FEBS Lett. 2014;588(2):288-297.

40. Navid F, Sondel PM, Barfield R, et al. Phase I trial of a novel anti-GD2 monoclonal antibody, Hu14.18K322A, designed to decrease toxicity in children with refractory or recurrent neuroblastoma. J Clin Oncol. 2014;32(14):1445-1452.

41. Gillies SD, Reilly EB, Lo KM, Reisfeld RA. Antibody-targeted interleukin 2 stimulates T-cell killing of autologous tumor cells. Proc Natl Acad Sci US A. 1992;89(4):1428-1432.

42. Vincent M, Bessard A, Cochonneau D, et al. Tumor targeting of the IL-15 superagonist RLI by an anti-GD2 antibody strongly enhances its antitumor potency. Int J Cancer. 2013;133(3):757-765.

43. Vincent M, Quéméner A, Jacques Y. Antitumor activity of an immunocytokine composed of an anti-GD2 antibody and the IL-15 superagonist RLI. Oncoimmunology. 2013;2(11):e26441.

44. Alvarez-Rueda N, Leprieur S, Clémenceau B, et al. Binding activities and antitumor properties of a new mouse/human chimeric antibody specific for GD2 ganglioside antigen. Clin Cancer Res. 2007;13(18 Pt 2):5613s-5620s.

45. Sabzevari H, Gillies SD, Mueller BM, Pancook JD, Reisfeld RA. A recombinant antibody-interleukin 2 fusion protein suppresses growth of hepatic human neuroblastoma metastases in severe combined immunodeficiency mice. Proc Natl Acad Sci U S A. 1994;91(20):9626-9630.

46. Hank JA, Surfus JE, Gan J, et al. Activation of human effector cells by a tumor reactive recombinant anti-ganglioside GD2 interleukin-2 fusion protein (ch14.18-IL2). Clin Cancer Res. 1996;2(12): 1951-1959.

47. Kendra K, Gan J, Ricci M, et al. Pharmacokinetics and stability of the ch14.18-interleukin-2 fusion protein in mice. Cancer Immunol Immunother. 1999;48(5):219-229.

48. Yamane BH, Hank JA, Albertini MR, Sondel PM. The development of antibody-IL-2 based immunotherapy with hu14.18-IL2 (EMD273063) in melanoma and neuroblastoma. Expert Opin Investig Drugs. 2009;18(7):991-1000. 
49. Osenga KL, Hank JA, Albertini MR, et al; Children's Oncology Group. A phase I clinical trial of the hu14.18-IL2 (EMD 273063) as a treatment for children with refractory or recurrent neuroblastoma and melanoma: a study of the Children's Oncology Group. Clin Cancer Res. 2006;12(6):1750-1759.

50. Shusterman S, London WB, Gillies SD, et al. Antitumor activity of hu14.18-IL2 in patients with relapsed/refractory neuroblastoma: a Children's Oncology Group (COG) phase II study. J Clin Oncol. 2010;28(33):4969-4975.

51. Mody R, Naranjo A, Hibbitts E, et al. Phase II Trial of Irinotecan/ Temozolomide with Dinutuximab/GMCSF (I/T/DIN/GMCSF) in Relapsed/Refractory Neuroblastoma: A Report from The Children's Oncology Group (COG). Abstract presented at: Advances in Neuroblastoma Research; May 9-12, 2018; San Francisco, CA, USA.

52. Marachelian A, Villablanca JG, Duvalyan A. A Phase I Study of Lenalidomide in Combination with ch14.18 and Isotretinoin (RA) in Patients with Refractory/Recurrent Neuroblastoma (RR-NB). Abstract presented at: Advances in Neuroblastoma Research; May 9-12, 2018; San Francisco, CA, USA.

53. Tran HC, Wan Z, Sheard MA, et al. TGFßR1 Blockade with Galunisertib (LY2157299) Enhances Anti-Neuroblastoma Activity of the Anti-GD2 Antibody Dinutuximab (ch14.18) with Natural Killer Cells. Clin Cancer Res. 2017;23(3):804-813.

54. Alderson KL, Luangrath M, Elsenheimer MM, et al. Enhancement of the anti-melanoma response of Hu14.18K322A by $\alpha \mathrm{CD} 40+\mathrm{CpG}$. Cancer Immunol, Immunother. 2013;62(4):665-675.

55. Altvater B, Landmeier S, Pscherer S, et al. 2B4 (CD244) signaling by recombinant antigen-specific chimeric receptors costimulates natural killer cell activation to leukemia and neuroblastoma cells. Clin Cancer Res. 2009;15(15):4857-4866.

56. Modak S, Cheung NK. Neuroblastoma: therapeutic strategies for a clinical enigma. Cancer Treat Rev. 2010;36(4):307-317.

57. Sivori S, Parolini S, Marcenaro E, et al. Involvement of natural cytotoxicity receptors in human natural killer cell-mediated lysis of neuroblastoma and glioblastoma cell lines. J Neuroimmunol. 2000;107(2):220-225.

58. Ogbomo H, Hahn A, Geiler J, Michaelis M, Doerr HW, Cinatl J. NK sensitivity of neuroblastoma cells determined by a highly sensitive coupled luminescent method. Biochem Biophys Res Commun. 2006;339(1):375-379.

59. Tarek N, Le Luduec JB, Gallagher MM, et al. Unlicensed NK cells target neuroblastoma following anti-GD2 antibody treatment. $J$ Clin Invest. 2012;122(9):3260-3270.

60. Lode HN, Xiang R, Dreier T, Varki NM, Gillies SD, Reisfeld RA. Natural killer cell-mediated eradication of neuroblastoma metastases to bone marrow by targeted interleukin-2 therapy. Blood. 1998;91(5):1706-1715.

61. Raffaghello L, Prigione I, Airoldi I, et al. Mechanisms of immune evasion of human neuroblastoma. Cancer Lett. 2005;228(1-2):155-161.

62. Wölfl M, Jungbluth AA, Garrido F, et al. Expression of MHC class I, MHC class II, and cancer germline antigens in neuroblastoma. Cancer Immunol Immunother. 2005;54(4):400-406.

63. Modak S, Cheung NK. Disialoganglioside directed immunotherapy of neuroblastoma. Cancer Invest. 2007;25(1):67-77.

64. Barker E, Mueller BM, Handgretinger R, Herter M, Yu AL, Reisfeld RA. Effect of a chimeric anti-ganglioside GD2 antibody on cell-mediated lysis of human neuroblastoma cells. Cancer Res. 1991;51(1):144-149.

65. Metelitsa LS, Gillies SD, Super M, Shimada H, Reynolds CP, Seeger RC. Antidisialoganglioside/granulocyte macrophage-colony-stimulating factor fusion protein facilitates neutrophil antibody-dependent cellular cytotoxicity and depends on FcgammaRII (CD32) and Mac-1 (CD11b/CD18) for enhanced effector cell adhesion and azurophil granule exocytosis. Blood. 2002;99(11):4166-4173.

66. Cheung IY, Hsu K, Cheung NK. Activation of peripheral-blood granulocytes is strongly correlated with patient outcome after immunotherapy with anti-GD2 monoclonal antibody and granulocyte-macrophage colony-stimulating factor. J Clin Oncol. 2012;30(4):426-432.
67. Chao MP, Alizadeh AA, Tang C, et al. Anti-CD47 antibody synergizes with rituximab to promote phagocytosis and eradicate non-Hodgkin lymphoma. Cell. 2010;142(5):699-713.

68. Siebert N, Jensen C, Troschke-Meurer S, et al. Neuroblastoma patients with high-affinity FCGR2A, -3A and stimulatory KIR 2DS 2 treated by long-term infusion of anti-GD $\mathrm{GD}_{2}$ antibody ch14.18/CHO show higher ADCC levels and improved event-free survival. Oncoimmunology. 2016;5(11):e1235108.

69. Delgado DC, Hank JA, Kolesar J, et al. Genotypes of NK cell KIR receptors, their ligands, and $\mathrm{Fc} \gamma$ receptors in the response of neuroblastoma patients to Hu14.18-IL2 immunotherapy. Cancer Res. 2010;70(23):9554-9561.

70. Venstrom JM, Zheng J, Noor N, et al. KIR and HLA genotypes are associated with disease progression and survival following autologous hematopoietic stem cell transplantation for high-risk neuroblastoma. Clin Cancer Res. 2009;15(23):7330-7334.

71. Erbe AK, Wang W, Carmichael L, et al. Neuroblastoma Patients' KIR and KIR-Ligand Genotypes Influence Clinical Outcome for Dinutuximab-based Immunotherapy: A Report from the Children's Oncology Group. Clin Cancer Res. 2018;24(1):189-196.

72. Diccianni MB, Gilman AL, Ozkaynak F. Impact of immune cell profiles on high-risk neuroblastoma treated with a COG phase III randomized immunotherapy study. Abstract presented at: Advances in Neuroblastoma Research; May 9-12, 2018; San Francisco, CA, USA.

73. Cheung NK, Sowers R, Vickers AJ, Cheung IY, Kushner BH, Gorlick R. FCGR2A polymorphism is correlated with clinical outcome after immunotherapy of neuroblastoma with anti-GD2 antibody and granulocyte macrophage colony-stimulating factor. J Clin Oncol. 2006;24(18):2885-2890.

74. Koehn TA, Trimble LL, Alderson KL, et al. Increasing the clinical efficacy of NK and antibody-mediated cancer immunotherapy: potential predictors of successful clinical outcome based on observations in high-risk neuroblastoma. Front Pharmacol. 2012;3:91.

75. Vanichapol T, Chutipongtanate S, Anurathapan U, Hongeng S. Immune Escape Mechanisms and Future Prospects for Immunotherapy in Neuroblastoma. Biomed Res Int. 2018;2018:1-11.

76. Asgharzadeh S, Salo JA, Ji L, et al. Clinical significance of tumorassociated inflammatory cells in metastatic neuroblastoma. $J$ Clin Oncol. 2012;30(28):3525-3532.

77. Hadjidaniel MD, Muthugounder S, Hung LT, et al. Tumor-associated macrophages promote neuroblastoma via STAT3 phosphorylation and up-regulation of c-MYC. Oncotarget. 2017;8(53): 91516-91529.

78. Hashimoto O, Yoshida M, Koma Y, et al. Collaboration of cancerassociated fibroblasts and tumour-associated macrophages for neuroblastoma development. J Pathol. 2016;240(2):211-223.

79. Gül N, van Egmond M. Antibody-dependent phagocytosis of tumor cells by macrophages: a potent effector mechanism of monoclonal antibody therapy of cancer. Cancer Res. 2015;75(23):5008-5013.

80. Munn DH, Cheung NK. Antibody-dependent antitumor cytotoxicity by human monocytes cultured with recombinant macrophage colony-stimulating factor. Induction of efficient antibody-mediated antitumor cytotoxicity not detected by isotope release assays. $J$ Exp Med. 1989;170(2):511-526.

81. Chen RL, Reynolds CP, Seeger RC. Neutrophils are cytotoxic and growth-inhibiting for neuroblastoma cells with an anti-GD2 antibody but, without cytotoxicity, can be growth-stimulating. Cancer Immunol Immunother. 2000;48(11):603-612.

82. Barker E, Reisfeld RA. A mechanism for neutrophil-mediated lysis of human neuroblastoma cells. Cancer Res. 1993;53(2):362-367.

83. Yeo KK, Hung L, Muthugounder S, Shirinbak S, Asgharzadeh S. Role of Neutrophils in Dinutuximab-mediated Antibody-Dependent Cellular Cytotoxicity (ADCC). Abstract presented at: Advances in Neuroblastoma Research; May 9-12, 2018; San Francisco, CA, USA.

84. Otto M, Barfield RC, Martin WJ, et al. Combination immunotherapy with clinical-scale enriched human gammadelta $T$ cells, hu14.18 antibody, and the immunocytokine Fc-IL 7 in disseminated neuroblastoma. Clin Cancer Res. 2005;11(23):8486-8491. 
85. Pauza CD, Liou ML, Lahusen T, et al. Gamma Delta T Cell Therapy for Cancer: It Is Good to be Local. Front Immunol. 2018;9:1305.

86. Fisher JP, Yan M, Heuijerjans J, et al. Neuroblastoma killing properties of $\mathrm{V} \delta 2$ and $V \delta 2$-negative $\gamma \delta \mathrm{T}$ cells following expansion by artificial antigen-presenting cells. Clin Cancer Res. 2014;20(22):5720-5732.

87. Zoine J, Sutton K, Knight K, Doering C, Goldsmith K, Spencer T. Gamma delta $(\gamma \delta)$ T Cell-Based Immunotherapy Augments Dinutuximab And Low Dose Chemotherapy to Regress Neuroblastoma Tumors. Abstract presented at: Advances in Neuroblastoma Research; May 9-12, 2018; San Francisco, CA, USA.

88. Cheung NK, Guo HF, Cheung IY. Correlation of anti-idiotype network with survival following anti-G(D2) monoclonal antibody $3 \mathrm{~F} 8$ therapy of stage 4 neuroblastoma. Med Pediatr Oncol. 2000;35(6):635-637.

89. Kramer K, Gerald WL, Kushner BH, Larson SM, Hameed M, Cheung NK. Disialoganglioside G(D2) loss following monoclonal antibody therapy is rare in neuroblastoma. Clin Cancer Res. 1998;4(9):2135-2139.

90. Cheung NK, Guo HF, Heller G, Cheung IY. Induction of Ab3 and Ab3' antibody was associated with long-term survival after antiG(D2) antibody therapy of stage 4 neuroblastoma. Clin Cancer Res. 2000;6(7):2653-2660.

91. Siebert N, Eger C, Seidel D, Jüttner M, Lode HN. Validated detection of human anti-chimeric immune responses in serum of neuroblastoma patients treated with ch14.18/CHO. J Immunol Methods. 2014;407:108-115.

92. Desai AV, Fox E, Smith LM, Lim AP, Maris JM, Balis FM. Pharmacokinetics of the chimeric anti-GD2 antibody, ch14.18, in children with high-risk neuroblastoma. Cancer Chemother Pharmacol. 2014;74(5):1047-1055.

93. Cheung IY, Kushner BH, Modak S, Basu EM, Roberts SS, Cheung NV. Phase I trial of anti-GD2 monoclonal antibody hu3F8 plus GM-CSF: Impact of body weight, immunogenicity and anti-GD2 response on pharmacokinetics and survival. Oncoimmunology. 2017;6(11):e1358331.

94. Lode HN, Schmidt M, Seidel D, et al. Vaccination with antiidiotype antibody ganglidiomab mediates a GD2-specific antineuroblastoma immune response. Cancer Immunol, Immunother. 2013;62(6):999-1010.

95. Schumacher-Kuckelkorn R, Volland R, Gradehandt A, Hero B, Simon $\mathrm{T}$, Berthold F. Lack of immunocytological GD2 expression on neuroblastoma cells in bone marrow at diagnosis, during treatment, and at recurrence. Pediatr Blood Cancer. 2017;64(1):46-56.

96. Terzic T, Cordeau M, Herblot S, et al. Expression of Disialoganglioside (GD2) in Neuroblastic Tumors: A Prognostic Value for Patients Treated With Anti-GD2 Immunotherapy. Pediatr Dev Pathol. 2018;21(4):355-362.

97. Keyel M, Davidson H, Nguyen T, Reynolds CP. Association of Anti-Tumor Activity in Neuroblastoma Patient-Derived Xenografts with Levels of GD2 Expression. Abstract presented at: Advances in Neuroblastoma Research; May 9-12, 2018; San Francisco, CA, USA.

98. Duman BB, Şahin B, Ergin M, Guvenc B. Loss of CD20 antigen expression after rituximab therapy of $\mathrm{CD} 20$ positive $\mathrm{B}$ cell lymphoma (diffuse large B cell extranodal marginal zone lymphoma combination): a case report and review of the literature. Med Oncol. 2012;29(2): 1223-1226.

99. Takei K, Yamazaki T, Sawada U, Ishizuka H, Aizawa S. Analysis of changes in CD20, CD55, and CD59 expression on established rituximab-resistant B-lymphoma cell lines. Leuk Res. 2006;30(5):625-631.

100. Terui Y, Mishima Y, Sugimura N, et al. Identification of CD20 C-terminal deletion mutations associated with loss of CD20 expression in non-Hodgkin's lymphoma. Clin Cancer Res. 2009;15(7):2523-2530.

101. Tsai PC, Hernandez-Ilizaliturri FJ, Bangia N, Olejniczak SH, Czuczman MS. Regulation of CD20 in rituximab-resistant cell lines and B-cell non-Hodgkin lymphoma. Clin Cancer Res. 2012;18(4):1039-1050.

102. Sotillo E, Barrett DM, Black KL, et al. Convergence of acquired mutations and alternative splicing of CD19 enables resistance to CART-19 immunotherapy. Cancer Discov. 2015;5(12):1282-1295.
103. Mukohara T. Mechanisms of resistance to anti-human epidermal growth factor receptor 2 agents in breast cancer. Cancer Sci. 2011;102(1): $1-8$.

104. Moss TJ, Reynolds CP, Sather HN, Romansky SG, Hammond GD, Seeger RC. Prognostic value of immunocytologic detection of bone marrow metastases in neuroblastoma. NEngl J Med. 1991;324(4):219-226.

105. Seeger RC, Danon YL, Rayner SA, Hoover F. Definition of a Thy-1 determinant on human neuroblastoma, glioma, sarcoma, and teratoma cells with a monoclonal antibody. J Immunol. 1982;128(2):983-989.

106. Seeger RC, Reynolds CP, Gallego R, Stram DO, Gerbing RB, Matthay KK. Quantitative tumor cell content of bone marrow and blood as a predictor of outcome in stage IV neuroblastoma: a Children's Cancer Group Study. J Clin Oncol. 2000;18(24):4067-4076.

107. Smith RG, Reynolds CP. Monoclonal antibody recognizing a human neuroblastoma-associated antigen. Diagn Clin Immunol. 1987;5(4):209-220.

108. Matsumura T, Sugimoto T, Sawada T, Amagai T, Negoro S, Kemshead JT. Cell surface membrane antigen present on neuroblastoma cells but not fetal neuroblasts recognized by a monoclonal antibody (KP-NAC8) Cancer Res. 1987;47(11):2924-2930.

109. Kramer K, Kushner BH, Modak S, et al. Compartmental intrathecal radioimmunotherapy: results for treatment for metastatic CNS neuroblastoma. J Neurooncol. 2010;97(3):409-418.

110. Picarda E, Ohaegbulam KC, Zang X. Molecular pathways: targeting B7-H3 (CD276) for human cancer immunotherapy. Clin Cancer Res. 2016;22(14):3425-3431.

111. Castellanos JR, Purvis IJ, Labak CM, et al. B7-H3 role in the immune landscape of cancer. Am J Clin Exp Immunol. 2017;6(4):66-75.

112. Castriconi R, Dondero A, Augugliaro R, et al. Identification of 4Ig$\mathrm{B} 7-\mathrm{H} 3$ as a neuroblastoma-associated molecule that exerts a protective role from an NK cell-mediated lysis. Proc Natl Acad Sci U S A. 2004;101(34):12640-12645.

113. Handgretinger R, Heubach F, Schlegel P. Targeting B7-H3 (CD276) in Neuroblastoma: Generation and In Vitro Evaluation of Different anti-CD276 Antibodies and Immunocytokines. Abstract presented at: Advances in Neuroblastoma Research; May 9-12, 2018; San Francisco, CA, USA.

114. Kadapakkam M, Majzner R, Xu P, Mackall C. B7-H3 CAR T Cells Mediate In Vitro and In Vivo Activity Against Neuroblastoma Xenografts. Abstract presented at: Advances in Neuroblastoma Research; May 9-12, 2018; San Francisco, CA, USA.

115. Kramer K, Kushner B, Modak S. A Curative Approach for Neuroblastoma Metastatic to the CNS: Safety and Efficacy of Intraventricular 131I-Labeled Monoclonal Antibody 8H9 Targeting B7-H3. Advances in Neuroblastoma Research. 2018;273.

116. Kramer K, Pandit-Taskar N, Zanzonico P. Curative targeting of CNS neuroblastoma micrometastases using the optimal therapeutic CSF dose delivered by compartmental radioimmunotherapy (cRIT). Abstract presented at: Advances in Neuroblastoma Research; May 9-12, 2018; San Francisco, CA, USA.

117. Liao R, Sun X, Zhang Y. The Clinical Significance of the Expression of B7H3 and PD-L1 in Neuroblastoma. Abstract presented at: Advances in Neuroblastoma Research; May 9-12, 2018; San Francisco, CA, USA.

118. Bosse KR, Raman P, Zhu Z, et al. Identification of GPC2 as an oncoprotein and candidate immunotherapeutic target in high-risk neuroblastoma. Cancer Cell. 2017;32(3):295-309.e12.

119. Weiner AK, Radaoui AB, Kendsersky NM. Integrative Mass Spectrometry and RNA-Sequencing Identifies Candidate Immunotherapeutic Targets in Neuroblastoma. Abstract presented at: Advances in Neuroblastoma Research; May 9-12, 2018; San Francisco, CA, USA.

120. Bosse K, Zhu Z, Lane M, et al. The antibody-drug conjugate D3-GPC2PBD potently eradicates neuroblastoma patient-derived xenografts. Abstract presented at: Advances in Neuroblastoma Research; May 9-12, 2018; San Francisco, CA, USA.

121. Kalos M, Levine BL, Porter DL, et al. T cells with chimeric antigen receptors have potent antitumor effects and can establish memory in patients with advanced leukemia. Sci Transl Med. 2011;3(95):95ra73. 
122. Lee DW, Kochenderfer JN, Stetler-Stevenson M, et al. T cells expressing CD19 chimeric antigen receptors for acute lymphoblastic leukaemia in children and young adults: a phase 1 dose-escalation trial. Lancet. 2015;385(9967):517-528.

123. Porter DL, Hwang WT, Frey NV, et al. Chimeric antigen receptor T cells persist and induce sustained remissions in relapsed refractory chronic lymphocytic leukemia. Sci Transl Med. 2015;7(303):303ra139.

124. Gargett T, Yu W, Dotti G, et al. GD2-specific CAR T cells undergo potent activation and deletion following antigen encounter but can be protected from activation-induced cell death by PD-1 blockade. Mol Ther. 2016;24(6):1135-1149.

125. Heczey A, Louis CU, Savoldo B, et al. CAR T Cells Administered in Combination with Lymphodepletion and PD-1 Inhibition to Patients with Neuroblastoma. Mol Ther. 2017;25(9):2214-2224.

126. Hoseini SS, Dobrenkov K, Pankov D, Xu XL, Cheung NK. Bispecific antibody does not induce T-cell death mediated by chimeric antigen receptor against disialoganglioside GD2. Oncoimmunology. 2017;6(6):e1320625.

127. Louis CU, Savoldo B, Dotti G, et al. Antitumor activity and long-term fate of chimeric antigen receptor-positive $\mathrm{T}$ cells in patients with neuroblastoma. Blood. 2011;118(23):6050-6056.

128. Moghimi B, Muthugounder S, Huang L, Shirinbak S, Asgharzadeh S. Preclinical Model of Gated GD2+B7H3 CAR-T Cell Therapy in Neuroblastoma. Abstract presented at: Advances in Neuroblastoma Research; May 9-12, 2018; San Francisco, CA, USA.

129. Cheung NK, Dyer MA. Neuroblastoma: developmental biology, cancer genomics and immunotherapy. Nat Rev Cancer. 2013;13(6):397-411.

130. Al Y, Batova A, Gribi R. Antibody-dependent cellular cytotoxicity (ADCC) in COG ANBL0032: a phase III randomized trial of chimeric anti-GD2 and GM-CSF/IL2 in high risk neuroblastoma following myeloablative therapy and autologous stem cell transplant (ASCT). $J$ Clin Oncol. 2004;22(14):2582-2582.
131. Gartrell J, Furman W, Shulkin B, Pappo A, Federico S. Induction chemotherapy with an anti-GD2 monoclonal antibody (dinutuximab) and cytokines in children with newly diagnosed high-risk neuroblastoma: a case series. Abstract presented at: Advances in Neuroblastoma Research; May 9-12, 2018; San Francisco, CA, USA.

132. Cheresh DA, Harper JR, Schulz G, Reisfeld RA. Localization of the gangliosides GD2 and GD3 in adhesion plaques and on the surface of human melanoma cells. Proc Natl Acad Sci U S A. 1984;81(18):5767-5771.

133. Irie RF, Sze LL, Saxton RE. Human antibody to OFA-I, a tumor antigen, produced in vitro by Epstein-Barr virus-transformed human B-lymphoid cell lines. Proc Natl Acad Sci U S A. 1982;79(18): 5666-5670.

134. Qian J, Liu T, Yang L, Daus A, Crowley R, Zhou Q. Structural characterization of N-linked oligosaccharides on monoclonal antibody cetuximab by the combination of orthogonal matrix-assisted laser desorption/ionization hybrid quadrupole-quadrupole time-of-flight tandem mass spectrometry and sequential enzymatic digestion. Anal Biochem. 2007;364(1):8-18.

135. Cheung NK, Guo H, Hu J, Tassev DV, Cheung IY. Humanizing murine IgG3 anti-GD2 antibody m3F8 substantially improves antibodydependent cell-mediated cytotoxicity while retaining targeting in vivo. Oncoimmunology. 2012;1(4):477-486.

136. Zhao Y, Niu C, Cui J. Gamma-delta $(\gamma \delta)$ T cells: friend or foe in cancer development? J Transl Med. 2018;16(1):3.
Biologics: Targets and Therapy

\section{Publish your work in this journal}

Biologics: Targets and Therapy is an international, peer-reviewed journal focusing on the patho-physiological rationale for and clinical application of Biologic agents in the management of autoimmune diseases, cancers or other pathologies where a molecular target can be identified. This journal is indexed on PubMed Central, EMBase, and Scopus.

\section{Dovepress}

The manuscript management system is completely online and includes a very quick and fair peer-review system, which is all easy to use Visit http://www.dovepress.com/testimonials.php to read real quotes from published authors. 